\title{
Relevant Factors to a Statistical Analysis of Overvoltages - Application to Three-Phase Reclosing of Compensated Transmission Lines
}

\author{
P. Mestas, M.C. Tavares \\ School of Electrical and Computer Engineering, University of Campinas (UNICAMP), Campinas, SP, Brazil \\ Email:pmestasv@dsce.fee.unicamp.br, cristina@dsce.fee.unicamp.br
}

Received April, 2013

\begin{abstract}
This paper describes the statistical study of important factors that influences transient over voltages resulting from three-phase reclosing of shunt compensated transmission lines. These factors include the model used for transmission line representation and the influence of line transposition. Additionally, the over voltages reduction to proper levels depending on the type of control technique are illustrated and analyzed in statistical terms. The evaluation covers three shunt compensation degrees. The digital simulations were performed using the PSCAD/EMTDC software.
\end{abstract}

Keywords: Transient Overvoltages; Three-phase Reclosing; Controlled Switching; Surge Arresters; Pre-insertion Resistor

\section{Introduction}

An important factor for the planning of extra high voltage transmission lines (TL) is the expectation of the switching over voltages level. For long transmission lines, the most severe switching over voltages results from fast three phase reclosing with trapped charge on the line.

A suitable evaluation of transient over voltages requires statistical studies, taking into account the randomness of the closing instant, and the pole-spread or time interval between closing of the first and final poles $[1,2]$. On the other hand, for the adequate representation of the electromagnetic transients on transmission line it should be considered that the longitudinal line parameters are strongly frequency dependent. Consequently, the transmission line model used for simulation of transient overvoltages is of great importance.

Likewise, it is important to verify if the representation of the transmission line by an actual transposition scheme compared to an ideal transposition scheme (balanced line) has influence on the overvoltage magnitude.

Another important factor during transmission line reclosing study is the method used to mitigate transient overvoltages in order to improve power quality levels. The most used techniques are surge arresters, controlled switching and pre-insertion resistors.

In this context, the goal of the present study is to evaluate relevant factors that influence transient overvoltages generated during three-phase reclosing of transmis- sion lines. These factors include the model used for the line representation and the influence of line transposition. In addition, the overvoltages reductions are analyzed from a viewpoint of the statistical behavior of circuit breaker.

\section{Power System Analyzed}

Figure 1 show the analyzed system based on an actual transmission system of $500 \mathrm{kV}$ and $1052 \mathrm{~km}$. The study is focused on the final segment of the line, which corresponds to a length of $252 \mathrm{~km}$ in the direction of B4 to B5. The line was switched using the CB7 circuit breaker.

The compensation scheme is composed of three single-phase reactors banks, with quality factor of 400 , grounded through a neutral reactor with quality factor of 40. The line parameters for the fundamental frequency $(60 \mathrm{~Hz})$ are shown in Table 1. Digital simulations were performed with PSCAD/EMTDC software.

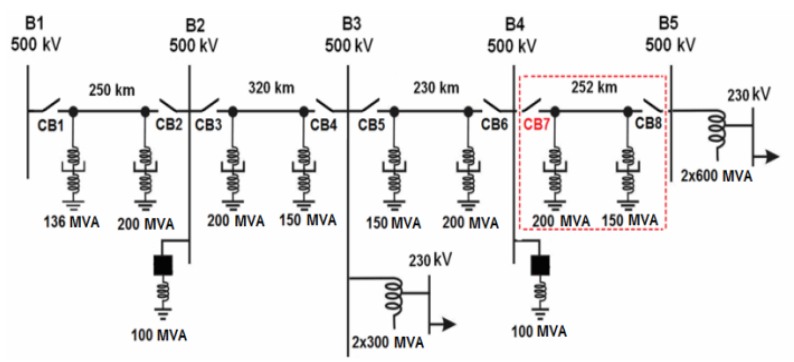

Figure 1.500 kV transmission system. 
Table 1. Basic line unitary parameters $-60 \mathrm{~Hz}$.

\begin{tabular}{ccc}
\hline Components & Longitudinal $(\Omega / \mathrm{km})$ & Transversal $(\mu \mathrm{S} / \mathrm{km})$ \\
\hline Non homopolar & $0.0161+\mathrm{j} 0.2734$ & $\mathrm{j} 6.0458$ \\
Homopolar & $0.4352+\mathrm{j} 1.4423$ & $\mathrm{j} 3.5237$ \\
\hline
\end{tabular}

\section{Three-phase Reclosing of TL}

The reclosing is a maneuver that consists in closing the contacts of circuit breaker after the transmission line opening in order to restore the power supply. Threephase reclosing may cause high transient overvoltages if the voltage source and the trapped charge on the line have opposite polarities.

\subsection{TL Reclosing without Shunt Reactive Compensation}

For uncompensated lines, the waveform can be approximated with a function of the form 1-cos $(\Omega t)$ with a suitable value of $\Omega$. The optimization of three-phase reclosing of such an uncompensated line is straightforward, and is achieved by breaker closure at a valley of the voltage signal and when the voltage is around the voltage zero crossing.

\subsection{TL Reclosing with Shunt Reactive Compensation}

The capacitive reactive power generated by transmission lines is usually compensated by the installation of shunt reactors at the ends of the line. The operational requirements of the system and the length of the line determine the level of the transmission line compensation.

The compensation level has an important effect on the voltage waveform across the contacts of the circuit breaker. As shown in Figure 2, the voltage across the contacts of the circuit breaker takes the form of beat. This beat is due to composition among the fundamental frequency of the system from one side of the contact breaker (system side) and the natural frequency of the line and reactors from the other side of the circuit breaker contact (line side) [3,4].

\subsection{Three-phase Reclosing of TL under Conditions of Internal Fault}

When the line opening occurs due to a fault on the transmission line, the sequence of events for the threephase reclosing includes: a fault occurrence, three-phase line opening to isolate the section under fault, waiting time for fault extinction and finally the reclosing of the transmission line. The phase under fault influences the waveform of the other two healthy phases, consequently the signals obtained are very complex and the expected beat is distorted in all three phases. For this reason, the three-phase reclosing scheme should be performed regarding to the time necessary for the extinction of the fault.

\subsection{Three-phase Reclosing of TL under Conditions of External Defects}

In this case, the sequence of events includes the automatic opening of the circuit breaker and subsequent reclosing after a predetermined time interval. The voltage across the circuit breaker presents a well defined beat, and the waveform is similar for the three phases.

The three-phase reclosing under conditions of external defects occurs when high values of switching overvoltages are erroneously interpreted as fault by any protective relay, resulting in the line dropping operation. It can also occur in the case of transmission lines on double-circuit, when the switching transient of one of the lines is coupled into the other line, which can also lead to incorrect operation of protection. Another condition could occur during a load rejection followed by opening the line at the sending end or also during the recovery of the power system after a large area black-out.

This work is focused on fast three-phase reclosing of shunt compensated transmission lines under conditions of external defects.

\section{Statistical Evaluation of Overvoltages}

For the evaluation of overvoltages it is important to conduct statistical studies to consider the randomness of the closing instant and the spread between the contacts of the circuit breaker. To this end, the circuit breakers are represented by statistic switches.

The statistic switches represents the variation of the closing instant by Gaussian curves for the three phases with a mean time and a standard deviation associated. Additionally, the variation of the mean time over a given period is characterized by a uniform distribution [5].

The statistic switch used in the simulations of this work was modeled according to [6]. The closing of the circuit breaker is randomly initiated over the period of a fundamental frequency cycle (in this case, over the 16.67

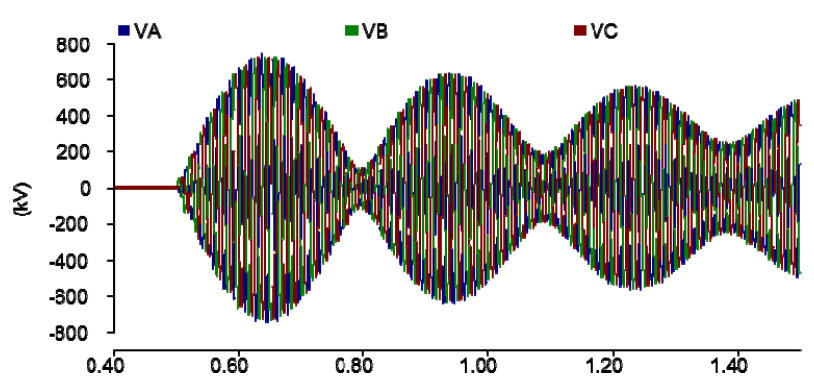

Figure 2. Voltage wave shape across circuit breaker poles. TL with compensation. 
$\mathrm{ms}$ ), and each pole closes in an interval defined by a normal distribution with a mean value and a standard deviation of $1 \mathrm{~ms}$.

Statistical evaluation was determined by analysis of variance (ANOVA) and F-test [7] with a significance level of $1 \%$ for the determination of the following aspects:

- Model used to represent the transmission line.

- Influence of line transposition scheme.

\subsection{Model used to represent the TL}

This evaluation aims to verify if differences can be found in statistical studies of reclosing regarding on the model used to represent the transmission line.

For this purpose were analyzed the following models of transmission lines, available in PSCAD program:

- Line model with frequency constant parameters or Bergeron Model [8].

- Line model with frequency dependence of longitudinal parameters or Phase Model [9].

For each case 300 shots were performed. One cycle of the fundamental frequency was considered for the variation range of the mean closing time. The analysis was performed for 90,70 and $50 \%$ of shunt compensation. The surge arresters at the line ends were not represented.

In Table 2 are presented the results obtained with the Bergeron Model and the Phase Model, for the three compensation levels. Higher overvoltages were verified when the line is modeled through Bergeron Model.

From the F-test of ANOVA shown in Table 3, for a significance level of $1 \%$, were found statistically significant differences between groups regarding to the transmission line model.

The Phase Model is numerically robust and more accurate for studies that require the frequency representation, different of fundamental frequency. Therefore, the Phase Model should be used in reclosing studies and will be used in the subsequent simulations.

Table 2. Transient overvoltages at line end.- analysis of transmission line model influence.

\begin{tabular}{cccccc}
\hline \multirow{2}{*}{$\begin{array}{c}\text { Comp. } \\
\text { degree } \\
(\%)\end{array}$} & $\begin{array}{c}\text { Transmission } \\
\text { Lines Models }\end{array}$ & \multicolumn{4}{c}{ Overvoltages at line end (p.u) } \\
\cline { 3 - 6 } & Bax. & Mean & $\begin{array}{c}\text { Standard de- } \\
\text { viation }\end{array}$ & $\begin{array}{c}\text { CV } \\
(\%)\end{array}$ \\
\hline 90 & Bergeron & 2.175 & 2.067 & 0.0620 & 3.042 \\
& Phases & 2.101 & 2.020 & 0.0530 & \\
70 & Bergeron & 2.449 & 2.270 & 0.0673 & 3.317 \\
50 & Phases & 2.358 & 2.214 & 0.0702 & \\
& Bergeron & 2.686 & 2.505 & 0.0939 & 3.921 \\
\hline
\end{tabular}

\subsection{Influence of TL Transposition}

In order to determine the influence of the transposition scheme, the transmission line was modeled for the following cases:

- Transmission line perfectly transposed (LPT).

- Transmission line with transposition scheme 1/61/3-1/3-1/6 (LRT).

For this evaluation were performed 300 shots for each case, with a variation range of the mean closing time of 01 cycle of the fundamental frequency. The transmission line model was represented by Phase Model and the study was performed for 90,70 and $50 \%$ of shunt reactive compensation. The surge arresters at the line ends were not represented.

From the results of Table 4 it is possible to observe that the representation of the line with an ideal transposetion scheme or with a real transposition scheme had influence on the overvoltages at the line ends. For all the analyzed cases the overvoltages had greater amplitude when the line is represented by a real transposition scheme.

Table 3. Analysis of variance of maximum overvoltages at line end.- Analysis of Line Model Influence.

\begin{tabular}{ccccccc}
\hline $\begin{array}{c}\text { Comp. } \\
\text { degree } \\
(\%)\end{array}$ & Source & $\begin{array}{c}\text { Freedom } \\
\text { Degrees }\end{array}$ & $\begin{array}{c}\text { Sum of } \\
\text { Squares }\end{array}$ & $\begin{array}{c}\text { Mean } \\
\text { Squares }\end{array}$ & F & $\begin{array}{c}\text { F Critic. } \\
* *\end{array}$ \\
\hline & BG & 1 & 0.216 & 0.2165 & 65.013 & 6.699 \\
90 & WG & 398 & 1.325 & 0.0033 & - & - \\
& Total & 399 & 1.542 & - & - & - \\
& BG & 1 & 0.324 & 0.3245 & 68.598 & 6.699 \\
70 & WG & 398 & 1.882 & 0.0047 & - & - \\
& Total & 399 & 2.207 & - & - & - \\
& BG & 1 & 0.422 & 0.4221 & 50.462 & 6.699 \\
\hline & WG & 398 & 3.329 & 0.0084 & - & - \\
\hline
\end{tabular}

Table 4. Transient Overvoltages at Line End.- Influence of Line Transposition.

\begin{tabular}{|c|c|c|c|c|c|}
\hline \multirow{2}{*}{$\begin{array}{c}\text { Comp. } \\
\text { degree } \\
(\%)\end{array}$} & \multirow{2}{*}{$\begin{array}{l}\text { Line Transposi- } \\
\text { tion Scheme }\end{array}$} & \multicolumn{4}{|c|}{ Overvoltages at line end (p.u) } \\
\hline & & Max. & Mean & $\begin{array}{l}\text { Standard } \\
\text { deviation }\end{array}$ & $\begin{array}{l}\mathrm{CV} \\
(\%)\end{array}$ \\
\hline \multirow{2}{*}{90} & LPT & 2.014 & 1.920 & 0.044 & \multirow{2}{*}{3.302} \\
\hline & LRT & 2.110 & 1.925 & 0.078 & \\
\hline \multirow{2}{*}{70} & LPT & 2.424 & 2.184 & 0.105 & \multirow{2}{*}{5.442} \\
\hline & LRT & 2.516 & 2.287 & 0.115 & \\
\hline \multirow{2}{*}{50} & LPT & 2.710 & 2.404 & 0.215 & \multirow{2}{*}{8.066} \\
\hline & LRT & 2.876 & 2.562 & 0.147 & \\
\hline
\end{tabular}


Table 5 shows the results of ANOVA. It is observed that for the transmission line with $90 \%$ of shunt compensation, the overvoltages for LTR are higher than for LPT, but this difference is small, therefore the $\mathrm{F}$ test shows differences statistically not significant between both groups. For lines with 70 and $50 \%$ of compensation, the F-test shows differences statistically significant between the groups.

The natural frequency of the line side is slightly different due to the variation of the line parameters caused by the transposition. This difference, in turn, results in the beating across the circuit breaker contacts with a different period regarding to the representation of the line with or without real compensation scheme. This phenomenon is most evident in highly compensated lines.

Based on the results it is recommended that for the analysis of transient overvoltages during three-phase reclosing the transmission lines must be represented with their actual transposition scheme. For the fundamental frequency, the line can be represented as ideally transposed, but this cannot be generalized to the whole range of frequencies involved in the transient phenomena.

\section{Analysis of Overvoltages Reduction Me- thods}

The negative impacts produced by random switching of circuit breakers during three-phase reclosing of transmission lines include reduction of equipment lifetime, breakdown of equipment in the substations, and degradation of power quality. Consequently, overvoltage control methods have to be adopted to provide suitable protection for the network.

The control methods analyzed in this work are: the use of metal oxide surge arresters, controlled switching and pre-insertion resistor.

Table 5. Analysis of variance of maximum overvoltages at line end.- Influence of Line Transposition.

\begin{tabular}{ccccccc}
\hline $\begin{array}{c}\text { Comp } \\
\text { degree } \\
(\%)\end{array}$ & Source & $\begin{array}{c}\text { Degrees } \\
\text { of free- } \\
\text { dom }\end{array}$ & $\begin{array}{c}\text { Sum of } \\
\text { Squares }\end{array}$ & $\begin{array}{c}\text { Mean } \\
\text { Squares }\end{array}$ & F & $\begin{array}{c}\text { F Crit. } \\
* *\end{array}$ \\
\hline 90 & WG & 398 & 1.60515 & 0.00403 & - & - \\
& Total & 399 & 1.60799 & - & - & - \\
& BG & 1 & 1.05151 & 1.05151 & 86.208 & 6.699 \\
70 & WG & 398 & 4.85450 & 0.01220 & - & - \\
& Total & 399 & 5.90601 & - & - & - \\
& BG & 1 & 2.48973 & 2.48973 & 73.243 & 6.6990 \\
& WG & 398 & 13.52900 & 0.03399 & - & - \\
\hline
\end{tabular}

For each of the three control methods analyzed 300 simulations were performed; one cycle of the fundamental frequency was considered for the variation range of the mean closing time; the transmission line was represented by Phases Model with transposition scheme $1 / 6-1 / 3-1 / 3-1 / 6$. The analysis was performed for 90,70 and $50 \%$ of shunt compensation and the surge arresters at the line ends were not represented, unless when it was the mitigation method.

\subsection{Metal Oxide Surge Arresters}

The metal oxide surge arresters have proven effective to limit overvoltages due its highly non-linear characteristic of the voltage related to the current [10].

For the simulations, all surge arresters are modeled according to the characteristic V-I curve. The following arresters were simulated:

- Class 5 - $420 \mathrm{kV}$ rated arrester with a protection level of $830 \mathrm{kV}$ at $2 \mathrm{kA}$, normally specified for $500 \mathrm{kV}$ Brazilian transmission lines.

- Class 5 - $396 \mathrm{kV}$ rated arrester with a protection level of $783 \mathrm{kV}$ at $2 \mathrm{kA}$.

- Class 3 - $360 \mathrm{kV}$ rated arrester with a protection level of $742 \mathrm{kV}$ at $2 \mathrm{kA}$.

Table 6 presents representative values of overvoltages at the line ends using the three classes of surge arresters for the three analyzed compensation levels. For the evaluation of critical conditions, the reclosing mean time is the second, third and fifth maximum of the voltage beat between the circuit breaker contacts.

The $396 \mathrm{kV}$ arresters provided a more effective performance and a greater reduction in overvoltage than the $420 \mathrm{kV}$ arresters for the three compensation levels.

The use of a $360 \mathrm{kV}$ rated arrester leads to an even greater reduction in the overvoltages at the line terminals. This case was simulated with an illustrative and comparative purpose because the appropriate selection of the surge arrester is determined not only by the protective

Table 6. Transient Overvoltages at Line End using Surge Arrester.

\begin{tabular}{ccccc}
\hline \multirow{2}{*}{$\begin{array}{c}\text { Comp. } \\
\text { degree } \\
(\%)\end{array}$} & $\begin{array}{c}\text { Rated } \\
\text { Voltage } \\
(\mathrm{kV})\end{array}$ & \multicolumn{2}{c}{ Overvoltages at line end (p.u) } \\
\cline { 3 - 5 } & 420 & 1.865 & 1.784 & 0.0501 \\
\hline \multirow{2}{*}{$90 \%$} & 396 & 1.783 & 1.732 & 0.0325 \\
& 360 & 1.704 & 1.679 & 0.0141 \\
& 420 & 1.906 & 1.832 & 0.0513 \\
& 396 & 1.814 & 1.761 & 0.0349 \\
$70 \%$ & 360 & 1.720 & 1.678 & 0.0273 \\
& 420 & 1.953 & 1.920 & 0.0200 \\
& 396 & 1.851 & 1.823 & 0.0163 \\
$50 \%$ & 360 & 1.752 & 1.729 & 0.0158 \\
\hline
\end{tabular}


level, but also by the operational characteristics of the system as a whole. Temporary overvoltage and maximum operational voltage are also relevant.

\subsection{Controlled Switching}

For three-phase reclosing, the controlled switching is applied so that the contacts of the circuit breaker must be closed at the minimum of the beat across the contacts of the circuit breaker (Figure 2). This region varies with the compensation level of the system and should be determined by an algorithm regarding to the measurement of voltage signals of the system, which are supplied to the algorithm.

Considering, for example, a dead time of $200 \mathrm{~ms}$, the optimal instant for three-phase reclosing corresponds to first, second and fourth beat minimum for transmission lines with 90,70 and $50 \%$ of compensation, respectively.

Two approaches to determining the optimal time of closing were analyzed:

a) Existing Method (EM)

In general way, the existing method described in $[5,11]$ identifies the first region of minimum beat and sends an order to close the circuit breaker in the next similar region. This method is based on the voltage polarities and zero crossing detection. The closing instant is determined when the voltage polarities at the source-side and the line-side are identical and when both signals cross by zero.

b) Proposed Method (PM)

The proposed method $[3,4]$ sends the closing command appropriately such that the poles closing occurs in the first minimum voltage beat across the circuit breaker, after the protection dead time. This method is based on the voltage wave shape across the circuit breaker, independent of voltage zero crossing.

Table 7 summarizes the simulation results and includes breaker reclosing mean times (RT). It can be seen that even though the overvoltage is only slightly smaller for the previously existing controlled reclosing method, the advantage that the proposed method is a much reduced reclosing time. It should be noted that the previously existing method was treated in an idealized manner, with its circuit breaker being closed at the second, third and fifth minimum voltage beats. This is optimistic, and in reality, the circuit breaker time would in all likelihood be further delayed. This delayed closing would occur particularly for low compensation levels, as the circuit breaker voltage has a less than pronounced beat and even certain intervals where there is no zero crossing at all, making it difficult for the existing method to identify the optimal reclosing instance.

\subsection{Pre-Insertion Resistor}

In this study, an existing $400-\Omega$ resistor was simulated, with a mean insertion time of $8 \mathrm{~ms}$. All three switch breaker poles of the main chamber of circuit breaker have the same mean closing time. The standard deviation of the closing time variation of the contacts is $0.5 \mathrm{~ms}$ for the auxiliary chamber and $1.0 \mathrm{~ms}$ for the main chamber of circuit breaker; truncated in $+/-2 \sigma$ in both cases.

Table 8 shows the overvoltages values at the receiving end and includes the mean reclosing time. For the evaluation of the resistor in critical conditions the reclosing mean time is the second, third and fifth maximum of the voltage beat between the circuit breaker contacts.

\subsection{Comparative Analysis of Control Methods}

For the three methods, the overvoltages were measured at the receiving end for the line with $90 \%$ shunt compensation. For the method of surge arrester was chosen for comparison the $396 \mathrm{kV}$ rated arrester located on both line terminals. In the case of controlled switching were presented both the existing method and the method proposed.

A graphical comparison of the results obtained by the studied methods is shown in Figure 3. It is observed that the controlled switching has the best performance for the overvoltages control.

It was also noted that, although the resistor is considered one of the most effective methods to reduce the amplitude of overvoltages, it presents a performance less efficient than the controlled switching. It should be considered that the mean reclosing time was stressed for both surge arrester and pre-insertion resistor cases.

Table 7. Transient Overvoltages at Line End using Controlled Switching.

\begin{tabular}{cccccc}
\hline $\begin{array}{c}\text { Comp. } \\
\text { degree } \\
(\%)\end{array}$ & $\begin{array}{c}\text { Me- } \\
\text { thod }\end{array}$ & $\begin{array}{l}\text { R.T. } \\
(\mathrm{ms})\end{array}$ & \multicolumn{2}{c}{ Overvoltages at line end (p.u) } \\
\cline { 5 - 6 } 90 & ME & 653 & 1.469 & 1.379 & $\begin{array}{c}\text { Standard } \\
\text { deviation }\end{array}$ \\
\hline \multirow{2}{*}{70} & MP & 318 & 1.291 & 1.223 & 0.0375 \\
& ME & 500 & 2.126 & 1.730 & 0.1851 \\
& MP & 405 & 1.833 & 1.563 & 0.1290 \\
50 & ME & 548 & 2.575 & 2.056 & 0.2559 \\
& MP & 490 & 2.499 & 2.019 & 0.2334 \\
\hline
\end{tabular}

Table 8. Transient Overvoltages at Line End using PreInsertion Resistor.

\begin{tabular}{ccccc}
\hline \multirow{2}{*}{$\begin{array}{c}\text { Comp. } \\
\text { Degree (\%) }\end{array}$} & $\begin{array}{c}\text { Reclosing } \\
\text { Time (ms) }\end{array}$ & \multicolumn{3}{c}{ Overvoltages at line end (p.u) } \\
\cline { 3 - 5 } & 500 & 1.748 & 1.583 & 0.0928 \\
70 & 558 & 2.287 & 2.080 & 0.1111 \\
70 & 487 & 2.785 & 2.510 & 0.1093 \\
50 & & & & Mean \\
\hline
\end{tabular}


Figure 4 shows the wave form when the control method is $396 \mathrm{kV}$ rated arresters at the line ends. The reclosing occurs $500 \mathrm{~ms}$. after of the line opening, which corresponds to the maximum of the second voltage beat between contacts of the circuit breaker.

Figure 5 shows the same operation, but this time using the proposed method of controlled switching. The reclosing occurs at the first minimum beat. It can be observed that not only the overvoltages were reduced with controlled switching as well as the waveform has a lower harmonic content.

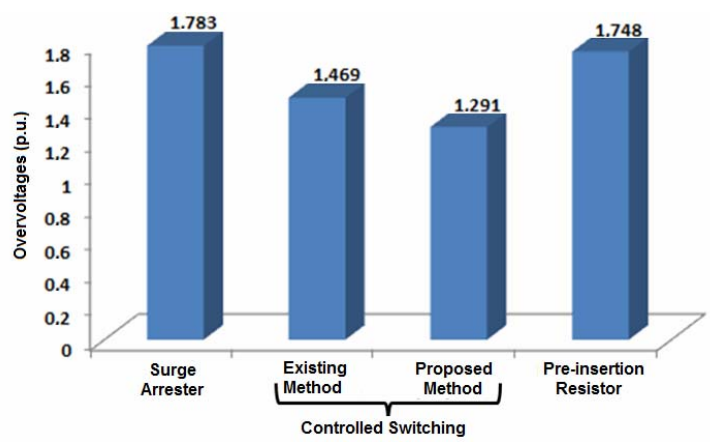

Figure 3. Comparison of maximum overvoltages at line end.

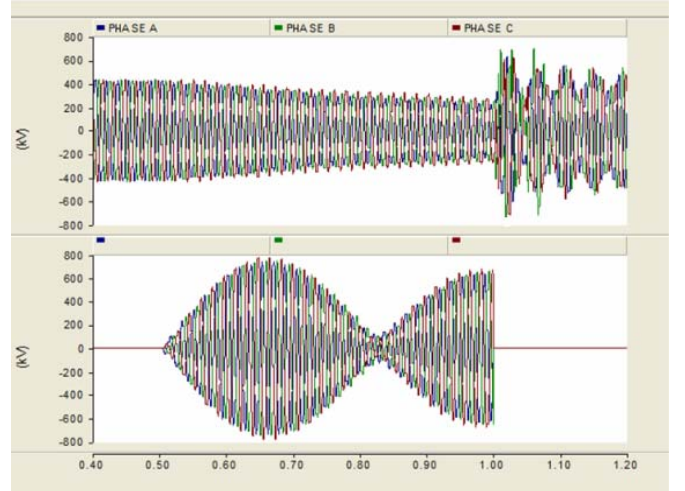

Figure 4. Line reclosing using $396 \mathrm{kV}$ rated arresters at line ends.

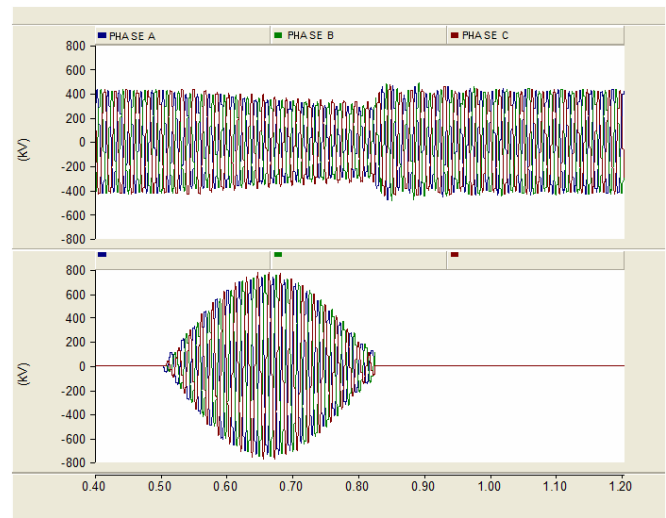

Figure 5. Line reclosing using controlled switching proposed method.

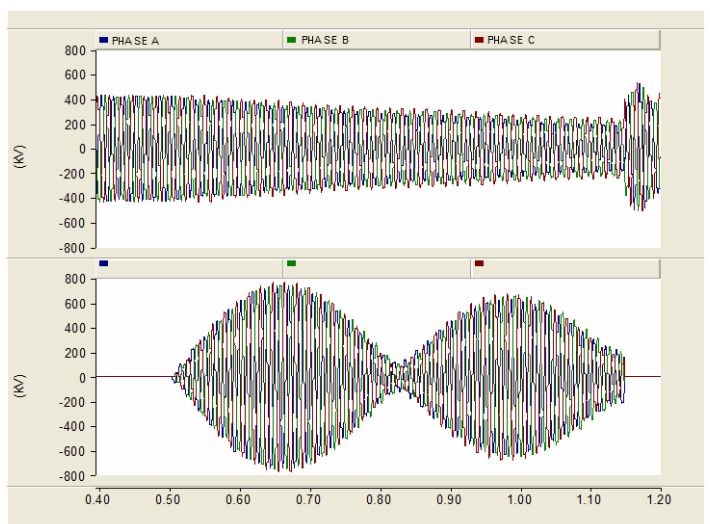

Figure 6. Reclosing using controlled switching. Existing method.

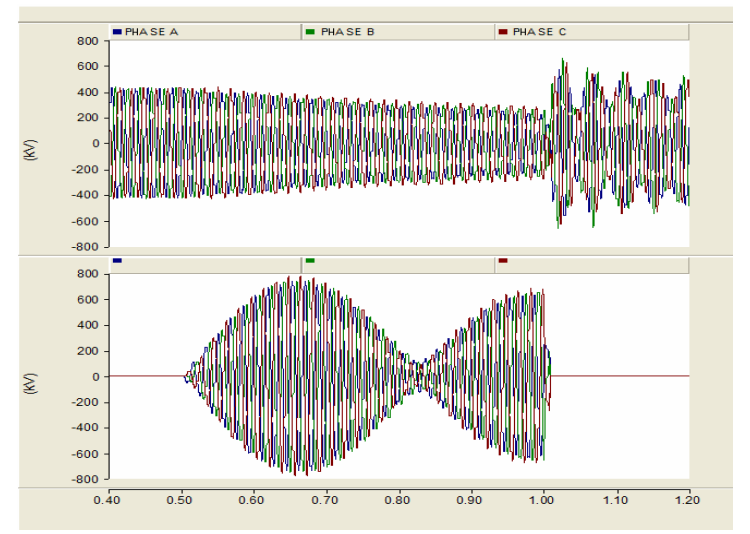

Figure 7. Line reclosing using pre-insertion resistor.

Figure 6 shows the voltage waveforms for the threephase reclosing using the existing method of controlled switching. The reclosing occurs at the second minimum beat. The method is also effective in reducing overvoltages, but it is noted that the reclosing time is increased.

Figure 7 corresponds to the use of pre-insertion resistor. The reclosing occurs at the maximum of the second voltage beat between contacts of the circuit breaker.

\section{Conclusions}

A statistical evaluation of overvoltages associated to three-phase reclosing of transmission lines was performed.

Regarding to the transmission line model, comparing results obtained using the Bergeron Model and Phase Model it was verified that higher overvoltages occur when the Bergeron Model is used. The latter model should not be used as it will lead to unnecessary higher insulation level. Therefore for three-phase reclosing studies, it is suggested the use of Phase Model because the accurate modeling of the line frequency dependence is of essential importance for the correct simulation of electromagnetic transient conditions. 
The representation of the transmission line ideally transposed or with an actual transposition scheme affects the results of overvoltages. In the case of three-phase reclosing, this difference is influenced by the variation of the line natural frequency and the compensation equipment at the line side.

Regarding the overvoltages mitigation methods, the use of $\mathrm{ZnO}$ surge-arresters with lower rated voltage (396 $\mathrm{kV}$ ) instead of the surge arresters normally specified (420 $\mathrm{kV}$ ) is an alternative to limit the overvoltages; however the use of this method would be more appropriate in combination with other control method.

For the three-phase reclosing of the studied system, the controlled switching is an effective method to reduce the overvoltages. It should be noted that using the proposed method overvoltages are slightly lower than for the existing method, however, the proposed method has a great advantage in reducing the reclosing time, thereby reducing the interruption time of power supply.

For the three-phase reclosing, the pre-insertion resistor is not a method as effective for the overvoltage reduction as in the case of energization, since the overvoltages can be high if the reclosing occurs near the maximum of the voltage beat between the circuit breaker contacts.

\section{Acknowledgements}

This work was supported by a grant from São Paulo Research Foundation-FAPESP and CNPq, Brazil.

\section{REFERENCES}

[1] J. A. Martinez, R. Natarajan and E. Camm, "Comparison of Statistical Switching Results Using Gaussian, Uniform and Systematic Switching Approaches," In: Proc. 2000 IEEE Power Engineering Society Summer Meeting, 2000, Seattle, Vol. 2, pp. 884-889.

[2] A. B. Fernandes and A. C. S. Lima, "Probabilistic Analysis of Transients Regarding Transmission Lines Automatic Reclosing" (Portuguese), In: VII Conferência
Brasileira sobre Qualidade da Energia Elétrica (VII CBQEE), 2007, SP, Brazil.

[3] P. Mestas, M. C. Tavares and A. M. Gole "Implementation and Performance Evaluation of a Reclosing Method for Shunt Reactor-Compensated Transmission Lines," IEEE Transactions on Power Delivery, Vol. 26, 2011, pp. 954-962.

[4] K. Froehlich, A. C. Carvalho, B. L. Avent, C. Hoelzl, W. Hofbauer, D. F. Peelo, M. Stanek, P. Hoegg and J. H. Sawada, "Controlled Closing on Shunt Reactor Compensated Transmission Lines Part II," IEEE Transactions on Power Delivery, Vol. 12, No. 2, 1997, pp. 741-746. doi: $10.1109 / 61.584360$

[5] L. Paris, "Basic Considerations of Magnitude Reduction of Switching Surges Due to Line Energization," IEEE Transactions on Power Apparatus and Systems, Vol. 87, No. 1, 1968, pp. 295-305. doi:10.1109/TPAS.1968.292002

[6] D. A. Woodford and L. M. Wedepohl, "Transmission Line Energization with Breaker Pre-Strike," In: IEEE WESCANEX 97: Conference on Communications, Power and Computing, Canada, 1997, pp. 105-108.

[7] D. C. Montgomery and G. C. Runger, "Applied Statistics and Probability for Engineers - Third Edition," New York: John Wiley \& Sons, Inc., 2003.

[8] J. R. Marti, L. Marti and H. Dommel, "Transmission Line Models for Steady-State and Transients Analysis," In: IEEE/NTUA Athens Power Tech Conference, 1993, Greece.

[9] A. Morched, B. Gustavsen and M. Tartibi, "A Universal Line Model for Accurate Calculation of Electromagnetic Transients on Overhead Lines and Cables," IEEE Transactions on Power Delivery, Vol. 14, No. 3, 1999. doi:10.1109/61.772350

[10] L. Stenstrom and M. Mobedjina, "Limitation of Switching Overvoltages by Use of Transmission Line Surge Arresters," In: CIGRE 998 sc 33 International Conference, Zagreb, 1998.

[11] L. Blahous, "Method for Determining the Time of Reclosing a Circuit Breaker and Device for Carrying out this Method," USA Patent 472439, Feb, 1988. 